\title{
Parasitismo e sítios de diapausa de adultos do percevejo marrom, Euschistus heros na região da Grande Dourados, MS
}

\author{
Parasitism and diapause sites of brown stink bug adults, Euschistus heros in the Great Dourados \\ Region, MS, Brazil
}

\author{
Karlla Barbosa Godoy ${ }^{\mathrm{I}}$ Crébio José Ávila' Marcela Marcelino Duarte $^{\mathrm{III}}$ \\ Carla Cristina Marques Arce ${ }^{\mathrm{IV}}$
}

\section{- NOTA -}

\section{RESUMO}

Entre os insetos que atacam a soja, o percevejo marrom Euschistus heros (Fabricius) é considerado uma das principais pragas. Os objetivos deste trabalho foram avaliar a ocorrência de parasitismo em adultos do percevejo marrom $\boldsymbol{E}$. hero, no período de cultivo da soja e de entressafra, e identificar seus sítios de diapausa no período de entressafra, na região da Grande Dourados, Mato Grosso do Sul (MS). Foram coletados adultos do percevejo em lavouras de soja, durante as safras 2004/05 e 2005/06, sendo as coletas realizadas semanalmente. No período de entressafra da soja de 2005 e 2006, foram realizadas inspeções em diferentes ambientes vegetais visando a constatar possíveis sítios de diapausa do percevejo, bem como avaliar a ocorrência de parasitismo nesses ambientes. Em cada coleta, foram individualizados 40 adultos em caixas gerbox contendo Ligustrum lucidum Ait. (Oleraceae), sendo os insetos observados durante um período de 40 dias. Os parasitoides foram armazenados em álcool $70 \%$ e encaminhados para identificação. $O$ índice natural de parasitismo de adultos de $\boldsymbol{E}$. heros amostrados no período de safra e de entressafra de soja variou de 0,0 a 5,0\%, considerando-se as diferentes coletas realizadas, sendo Hexacladia smithii Ashmead (Hymenoptera: Encyrtidae) a única espécie de parasitoide ocorrente. No período de entressafra, foi verificada maior incidência do percevejo $\boldsymbol{E}$. heros em folhas secas de mangueira (Mangifera indica L.) caídas no chão, evidenciando que esse ambiente é um importante sítio de diapausa para essa praga na região.

Palavras-chave: incidência natural, Hexacladia smithii, parasitoide, soja.

\section{ABSTRACT}

Among the insects that attack soybeans, brown stink bug Euschistus heros (Fabricius) is considered a major pest. The aim of this research was to evaluate the occurrence of parasitism in adults of brown stink bugs $\boldsymbol{E}$. heros during soybean crop season and to identify diapause sites during the period of soybean absence in the great region of Dourados, MS. Adults of brown stick bugs were collected weekly in soybean crops during the 2004/05 and 2005/06 growing seasons. In the offseason soybean in 2005 and 2006 inspections were conducted in different environments to find possible sites of bugs' diapause , and to evaluate the occurrence of parasitism in these environments. For each sampling date, 40 adults were put inside one gerbox, fed with Ligustrum lucidum Ait. (Oleraceae), and observed for a period of 40 days. Parasitoids were kept in alcohol $70 \%$ and send to identification. The natural incidence of parasitism of adults collected in the period with and without soybean crops varied from $0.0 \%$ and $5.0 \%$, and considering different samples, Hexacladia smithii Ashmead (Hymenoptera: Encyrtidae) was the only one parasitoid found. During the period of soybean absence was observe the highest incidence of $\boldsymbol{E}$. heros on dry fallen leaves of Mangifera indica L., showing that this environment is an important diapause sites for this pest in this region.

Key words: Hexacladia smithiiz, natural incidence, parasitoid, soybean.

Os percevejos fitófagos são os principais insetos-praga que causam perdas na cultura da soja,

IDepartamento de Ciências Agrárias, Universidade Federal do Acre (UFAC), Rio Branco, AC, Brasil. E-mail: godoy.k.b@hotmail.com. Autor para correspondência.

IEmbrapa Agropecuária Oeste, Dourados, MS, Brasil.

IIIUniversidade Federal da Grande Dourados (UFGD), Dourados, MS, Brasil.

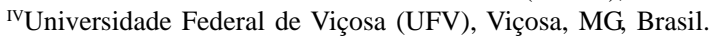


sendo as espécies da família Pentatomidae as de maior importância (PANIZZI \& SLANSKY JR., 1985). O percevejo marrom Euschistus heros (Fabricius) (Hemiptera: Pentatomidae) é uma das espécies mais abundante dentro do complexo de percevejos-praga de soja (PANIZZI \& SLANSKY JR., 1985), especialmente na região Centro-oeste, onde o clima é quente e com pouca variação térmica, o que favorece um maior número de gerações dessa espécie de percevejo (CIVIDANES \& PARRA, 1994).

O parasitoide Hexacladia smithii Ashmead (Hymenoptera: Encyrtidae) foi relatado pela primeira vez no Brasil no norte do Estado do Paraná, em adultos de $\boldsymbol{E}$. heros, na cultura da soja (CORRÊA-FERREIRA et al., 1998). Adultos de $\boldsymbol{E}$. heros parasitados por $\boldsymbol{H}$. smithii sofrem uma redução na sobrevivência e na atividade alimentar, o que evidencia a importância desse parasitoide como agente de controle biológico natural (NUNES \& CORRÊA-FERREIRA, 2002).

Na época de entressafra, muitos percevejos deslocam-se para abrigos de sobrevivência, podendo permanecer nesses locais em estado de diapausa. No norte do Paraná, observou-se que, após a colheita da soja, adultos de $\boldsymbol{E}$. heros alojam-se sob folhas secas, onde permanecem em estado de dormência até a próxima safra de verão, aumentando o nível populacional do percevejo (PANIZZI \& NIVA, 1994). No entanto, no Estado de Mato Grosso do Sul, os sítios de diapausa do percevejo marrom ainda não são conhecidos.

A identificação e conservação dos inimigos naturais e a localização dos refúgios dos adultos em diapausa nos agroecossistemas são algumas estratégias adotadas no manejo integrado de pragas (BATISTA FILHO et al., 2003). Dessa forma, os objetivos deste trabalho foram avaliar a ocorrência de parasitismo natural em adultos do percevejo marrom $\boldsymbol{E}$. heros, no período de cultivo da soja e de entressafra, bem como identificar os seus sítios de refúgio durante o período sem o cultivo da soja, na região da Grande Dourados, MS.

O parasitismo em adultos de $\boldsymbol{E}$. heros foi avaliado durante as safras de soja de 2004/05 e 2005/ 06 , sendo as coletas realizadas semanalmente, na região da Grande Dourados, MS. No período reprodutivo da soja, foram coletados adultos de $\boldsymbol{E}$. heros em lavouras dos Municípios de Dourados, Ponta Porã, Itaporã e Caarapó. Nos períodos da entressafra da soja dos anos de 2005 e 2006, foram inspecionados diferentes ambientes vegetais nos Municípios de Dourados e Itaporã, visando a constatar possíveis sítios de diapausa do percevejo, bem como avaliar a ocorrência de parasitismo nos adultos coletados nesses ambientes. Em cada coleta, foram individualizados 40 adultos em caixas gerbox contendo Ligustrum lucidum Ait. (Oleraceae), sendo os percevejos observados durante um período de 40 dias. Após esse período, os adultos sobreviventes foram dissecados para exame, já que o percevejo poderia estar parasitado sem que $o$ parasitoide tivesse emergido do seu corpo (CORRÊAFERREIRA et al., 1998). Os parasitoides emergidos dos adultos coletados, tanto na safra, quanto na entressafra, foram colocados em álcool 70\% e, posteriormente, encaminhados a especialistas para identificação.

Na safra de 2004/05, os adultos coletados em Ponta Porã apresentaram maior índice de parasitismo $(2,2 \%)$ do que aqueles coletados nas demais localidades. Os percevejos provenientes de Itaporã e Caarapó apresentaram 1,25\% de parasitismo, respectivamente, diferentemente dos provenientes de Dourados, onde não foram encontrados adultos parasitados nessa safra. Isso provavelmente ocorreu porque as áreas de coleta dos Municípios de Ponta Porã, Itaporã e Caarapó estão próximas à área de mata, ou seja, áreas de refúgio para muitos insetos. Segundo MURTA et al. (2008), o controle natural das pragas pode ser mais eficiente por meio da preservação dos fragmentos de vegetação nativa existentes ao redor das culturas que servem de refúgio para os inimigos naturais. Dos adultos de $\boldsymbol{E}$. heros coletados em soja na safra 2005/06, observou-se parasitismo de 5,0\% em Caarapó e de 4,0\% em Ponta Porã, já nas outras localidades não foram encontrado percevejos para avaliação do parasitismo. Houve um aumento no índice de parasitismo de uma safra para outra entre os Municípios de Caarapó e Ponta Porã porque, além dessas áreas de coletas estarem próximas de áreas de mata, provavelmente houve também diminuição na aplicação de inseticidas ou a utilização de inseticidas seletivos para o controle desse percevejo.

Na entressafra de soja de 2005 e 2006, em Ponta Porã, foram coletados adultos do percevejo em capim carrapicho (Cenchurs echinatus L.), colonião (Panicum maximum Jacq.) e trapoeraba (Commelina bengahalensis L.), representando 2,5\% de parasitismo, índice superior ao observado para os percevejos coletados na mucuna (Mucuna aterrimum Piper \& Tracy), em Itaporã (0,56\%), e nas folhas de mangueira Mangifera indica L. (Anacardiaceae), em Dourados $(0,27 \%)$. Todos os parasitoides emergidos dos percevejos coletados no período da entressafra também foram pertencentes à espécie $\boldsymbol{H}$. smithi.

CORRÊA-FERREIRA et al. (1998) constataram a incidência de parasitismo de $\boldsymbol{H}$. smithii em adultos de $\boldsymbol{E}$. heros, no Estado do Paraná, constituindo-se no primeiro registro de ocorrência desse parasitoide em percevejos fitófagos da soja no 
Brasil. Segundo esses autores, a incidência natural de parasitismo de $\boldsymbol{H}$. smithii em adultos de $\boldsymbol{E}$. heros variou de 0,6 a 39,5\%, e sua presença foi observada na cultura da soja nos meses de dezembro e janeiro, reduzindo a capacidade de multiplicação dessa praga na lavoura. Os adultos parasitados encontrados neste trabalho, no período de safra (2004/05 e 2005/06) da soja e de entressafra (2005 e 2006), na região da Grande Dourados, MS, apresentaram uma incidência natural de parasitismo em adultos de $\boldsymbol{E}$. heros que variou de 0,0 a 5,0\%, considerando-se as diferentes coletas realizadas. $\boldsymbol{H}$. smithii foi constatada como a única espécie de parasitoide ocorrente nas safras e entressafras estudadas.

Em Dourados, durante a entressafra de 2005 (abril a agosto), foram coletados 865 percevejos em folhas secas caídas de mangueira, enquanto que, em Itaporã, foram coletados 349 percevejos em mucuna, capim carrapicho, colonião e trapoeraba. Na entressafra de 2006 (abril a agosto), foram coletados 323 percevejos em folhas secas caídas de mangueiras em Dourados e 334 percevejos em folhas secas de mamona Ricinus communis L. (Euphorbiaceae), capim carrapicho, colonião e trapoeraba em Itaporã. PANIZZI \& NIVA (1994) observaram a ocorrência de $\boldsymbol{E}$. heros sob folhas caídas de mangueira e folhas secas de café durante os meses de abril a outubro. No ano de 2005, foi encontrado maior número de percevejos em maio, enquanto que, em 2006, os meses de maior ocorrência foram maio e junho (Figura 1). PANIZZI \& NIVA(1994) também obtiveram picos de coleta verificados no início do mês de maio e na segunda quinzena de maio. Isso provavelmente aconteceu porque nos meses de maio e junho a soja já havia sido colhida, então os insetos poderiam migrar para os sítios de refúgio. Nos meses subsequentes, houve uma queda na ocorrência desse inseto nos sítios de refúgio provavelmente por ser uma época de semeadura do milho e esses insetos poderiam migrar para essa cultura.

Observou-se, durante as coletas, que os percevejos apresentavam normalmente pouca mobilidade, permaneciam no interior de folhas enroladas ou até mesmo estáticos com a posição ventral orientada para cima, o que possivelmente evidenciava que os insetos estavam em condições de diapausa. Esse comportamento também foi observado por PANIZZI \& NIVA(1994) e MOURÃO \& PANIZZI (2000) em mangueira, guandu (Cajanus cajan L.), girassol (Helianthus annuus L.), carrapicho de carneiro (Acanthospermum hispidium L.) e amendoim bravo (Pterogyne nitens Tul.) no Estado do Paraná.

Adultos de $\boldsymbol{E}$. heros apresentam parasitismo, tanto na safra, como na entressafra da cultura da soja, sendo os os percevejos encontrados nesse período de entressafra em folhas secas de mangueira, mucuna e mamona considerando estes seus sítios de diapausa.

\section{AGRADECIMENTOS}

Os autores agradecem à Dra. Beatriz Spalding Corrêa-Ferreira, pela identificação do parasitoide encontrado nesta pesquisa, e à Fundação de Apoio ao Desenvolvimento do Ensino, Ciência e Tecnologia - FUNDECT, por ter financiado esta ação de pesquisa.

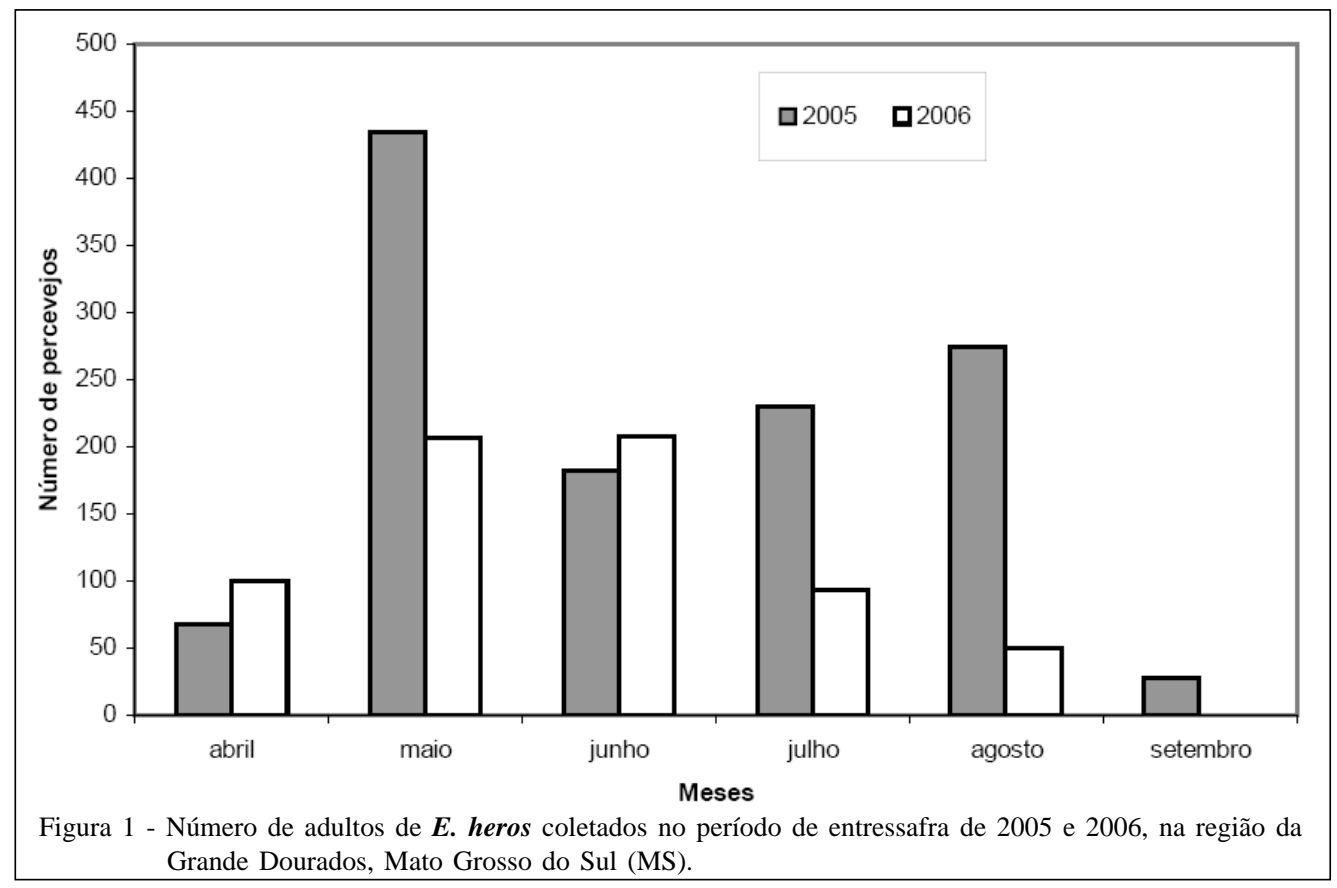

Ciência Rural, v.40, n.5, mai, 2010. 


\section{REFERÊNCIAS}

CIVIDANES, F.J.; PARRA, J.R.P. Zoneamento ecológico de Nezara viridula (L.), Piezodorus guildinii (West.) e Euschistus heros (Fabr.) (Heteroptera: Pentatomidae) em quatro Estados produtores de soja no Brasil. Anais da Sociedade Entomológica do Brasil, v.23, p.219-226, 1994.

CORRÊA-FERREIRA, B.S. et al. Ocorrência do parasitóide Hexacladia smithii Ashmead em adultos de Euschistus heros (F.) no Brasil. Anais da Sociedade Entomológica do Brasil, v.27, n.3, p.495-498, 1998. Disponível em: <http://www.scielo.br/pdf/aseb/ v27n3/v27n3a22.pdf>. Acesso em: 05 jan. 2009. doi: 10.1590/ S0301-80591998000300022.

BATISTA FILHO, A. et al. Manejo integrado de pragas em soja: impacto de inseticidas sobre inimigos naturais. Arquivos do Instituto Biológico, v.70, n.1, p.61-67, 2003.

MOURÃO, A.P.M.; PANIZZI, A.R. Diapausa e diferentes formas sazonais em Euschistus heros (Fabr.) (Hemiptera: Pentatomidae) no norte do Paraná. Anais da Sociedade Entomológica do Brasil, v.29, n.2, p.205-218, 2000. Disponível em: <http:// www.scielo.br/pdf/aseb/v29n2/v29n2a02.pdf>. Acesso em: 05 jan. 2009. doi: 10.1590/S0301-80592000000200002.
MURTA, A.F. et al. Efeitos de Remanescentes de Mata Atlântica no Controle Biológico de Euselasia apisaon (Dahman) (Lepidoptera: Riodinidae) por Trichogramma maxacalii (Voegelé e Pointel) (Hymenoptera: Trichogrammatidae). Neotropical Entomology, v.37, n.2, p.229-232, 2008. Disponível em: <http://www.scielo.br/pdf/ne/v37n2/ a19v37n2.pdf>. Acesso em: 03 set. 2009. doi: 10.1590/S1519566X2008000200019.

NUNES, M.C.; CORRÊA-FERREIRA, B.S. Desempenho alimentar e sobrevivência de Euschistus heros parasitado por Hexacladia smithii em sementes de soja. Pesquisa Agropecuária Brasileira, v.37, n.9, p.1219-1223, 2002. Disponível em: <http://www.scielo.br/pdf/pab/v37n9/ 13194.pdf>. Acesso em: 05 jan. 2009. doi: 10.1590/S0100204X2002000900003.

PANIZZI, A.R.; NIVA, C.C. Overwintering strategy of the bown stink bug in northern Paraná. Pesquisa Agropecuária Brasileira, v.29, n. 3, p.509-511, 1994.

PANIZZI, A.R.; SLANSKY F. Jr. Review of phytophagous pentatomids (Hemiptera: Pentatomidae) associated with soybean in Americas. Florida Entomologist, v.68, n.1, p.184214, 1985. 